\title{
Well-Being, New Technologies, and Clinical Evidence for Family Physicians
}

\author{
Dean A. Seehusen, MD, MPH, Marjorie A. Bowman, MD, MPA, and \\ Anne Victoria Neale, PhD, MPH
}

This special issue contains several articles on well-being. Not surprisingly, many of these articles are specifically about burnout. The evidence shows differences in the rates of burnout between men and women family physicians as well as their responses. Clinical team structure and organizational change also contribute to burnout. What about the electronic medical record? We are also reminded that burnout is an international issue. There are also several articles on how technology is changing the way family physicians practice. Two articles report on issues regarding screening for frequently seen clinical entities, specifically breast cancer and alcohol misuse. There are also articles looking at the cost of medical assistant turnover in practices, the impact of continuity with a provider on the retention of patients in clinical trials, and much more of interest to family physicians. ( $\mathrm{J}$ Am Board Fam Med 2020;33:347-349.)

\section{The Well-Being Special Issue}

It was not surprising that most of the manuscripts submitted to the Fournal of the American Board of Family Medicine in response to our "call for articles" on well-being were about burnout. Burnout is clearly among the most pressing issues facing family physicians today. Looking at the articles we received, we can say that burnout is a widespread problem in family medicine and that many of the contributors to burnout have been identified. Now the question is "how can we effectively deal with burnout on a system-wide basis"? We are asking you, family medicine researchers!

Survey data from family physicians registering for the American Board of Family Medicine certification examination look at care team structure and efficiency to determine how these factors contribute to family physician burnout. These results provide additional data for leaders and administrators to consider as they design and implement their health care delivery teams. ${ }^{1}$

Three reports look at how organizational structure and features of the care environment affect rates of burnout. Khanna et $\mathrm{al}^{2}$ present a tool that can help evaluate culture and identify areas for improvement. In the United States Army, an initiative to improve resiliency through a more holistic

Conflict of interest: The authors are editors of the $7 A B F M$. approach to patient care failed to reduce burnout in the short term. ${ }^{3}$ In a survey from Virginia, Goldberg et $\mathrm{al}^{4}$ include providers and staff, exploring how individuals' psychological responses to organizational change was related their risk of burnout. More interesting findings include the impact of organizational change on individuals.

Eden et $\mathrm{al}^{5}$ report on burnout rate variation among family physicians by gender and age. How do physicians deal with burnout? It turns out the answer to that question also varies by the physician's gender. ${ }^{6}$ The 2 above mentioned studies ${ }^{5,6}$ suggest that health care leaders and policymakers cannot attempt to reverse the current rates of burnout through a 1-size-fits-all model. Groups experience and respond differently to the stresses of being a family physician. The system solutions are likely to require multiple types of interventions.

Two other articles remind us that burnout and job dissatisfaction are widespread among primary care providers internationally. Torres et $\mathrm{al}^{7}$ report on burnout among Spanish family physicians caring for fibromyalgia patients. From China, where the medical system is quite different from the American system, Liqing et $\mathrm{al}^{8}$ report similar struggles. Perhaps these common factors suggest potential solutions?

Two articles provide a glimpse into the stress that increasing electronic patient communication can put on offices and providers. Patient portals are 
an important way for patients to gain increased access to health care, and they have been shown to be popular and facilitate more direct communication. What fallout does a clinic face when attempting to meet the demands of a newly implemented patient portal? Not surprisingly, people and time are among the answers. ${ }^{9}$ Margolius et $\mathrm{al}^{10}$ report factors that influence the number of electronic health record inbox messages that primary care providers receive. The results are unlikely to surprise those of us who spend a good deal of our day on the electronic health record.

\section{New Computer-Based Support for Family Physician Care}

Social determinants of health (SDH) have been the subject of numerous recent reports in the Journal of the American Board of Family Medicine. In this issue, Bambekova et $\mathrm{al}^{11}$ report on a new tool, The Population Health Assessment Engine that allows use of registry data on SDH and geocoding to identify patient populations at risk. The authors point out several potential uses of this new tool, including outreach to patients and educating tomorrow's family physicians to more effectively address SDH.

Artificial intelligence and machine learning are coming soon to a family medicine practice near you! We expect to see much more family medicine research on artificial intelligence and machine learning in the coming years. In this issue: can machine learning identify patients at increased risk of unhealthy drinking habits? A report by Bonnell et $\mathrm{a}^{12}$ shows how machine learning could play a large role in the way we approach population health in the future. Another application of the power of computing in family medicine is reported on by Ludden et $\mathrm{al}^{13}$, showing that modeling can be used to help identify communities at greatest risk for undetected hepatitis $\mathrm{C}$ infection, thereby allowing for more targeted screening programs.

\section{Clinical Evidence}

Screening for disease is 1 of the most important services family physicians perform on a daily basis. Two articles in this issue explore challenges associated with knowing who to screen, when to screen, and how to screen. Older women have been excluded from many breast cancer screening trials. This is unfortunate because they are at the highest risk of developing breast cancer. The result is a lack of consistent recommendations for screening in women over age 75 . Schrager et $\mathrm{al}^{14}$ provide an exceptional clinical review evaluating the evidence and providing sound advice for discussing the risks and benefits of screening with women in this agegroup.

Is the effectiveness of screening for early cognitive decline influenced by the strategy used? Specifically, how does relying on the patient's subjective input influence the process? Hess et $\mathrm{al}^{15}$ explore these questions and report on which strategies are most likely to accurately identify cases.

Medical assistants (MAs) have been getting more attention as key members of the primary care workforce. MAs are can improve patient flow and ease the work burden on nursing staff in primary care clinics. One underreported issue with MAs is their significant turnover rate. An excellent example of cost analysis in the primary care setting addresses this issue and its implications. ${ }^{16}$

We have long known the challenges of retaining certain populations, such as minorities, women, and patients from low socioeconomic backgrounds, in clinical trials. Friedman et $\mathrm{al}^{17}$ explores characteristics that predict successful retention in clinical trials. The results suggest that having a primary care provider may be key to recruiting and retaining patients in trials.

DeVoe et $\mathrm{al}^{18}$ insightfully explain why payment models must shift before family physicians can truly focus on patient health. In a separate piece, Bair ${ }^{19}$ reminds us that everyone we interact with in the health care environment has a story and potential.

To see this article online, please go to: http://jabfm.org/content/ 33/3/347.full.

\section{References}

1. Dai M, Willard-Grace R, Knox M, et al. Team configurations, efficiency, and family physician burnout. J Am Board Fam Med 2020;33:368-377.

2. Khanna N, Montgomery R, Klyushnenkova E. Joy in work for clinicians and staff: identifying remedial predictors of burnout from the Mini-Z survey. J Am Board Fam Med 2020;33:357-367.

3. Coleman AM, Hartzell MM, Oh RC, Funari TS, Rivera LO, Brown JA. Improving resilience and combating burnout in US army health care teams. J Am Board Fam Med 2020;33:440-445.

4. Goldberg D, Soylu TG, Grady VM, Kitsantas P, Grady JD, Nichols LM. Indicators of workplace 
burnout among physicians, advanced practice clinicians and staff in small to medium-sized primary care practices. J Am Board Fam Med 2020;33:378-385.

5. Eden AR, Jabbarpour Y, Morgan ZJ, Wilkinson E, Peterson LE. Burnout among family physicians by gender and age. J Am Board Fam Med 2020;33:355-356.

6. Eden AR, Jabbarpour Y, Morgan Z, Dai M, Coffman M, Bazemore A. Gender differences in personal and organizational mechanisms to address burnout among family physicians. J Am Board Fam Med 2020;33:446-451.

7. Torres X, Ojeda B, Collado A, et al. Characterization of burnout among Spanish family physicians treating fibromyalgia patients: the EPIFFAC study. J Am Board Fam Med 2020;33:386-396.

8. Liqing L, Yong G, Heng J, et al. Job satisfaction and its associated factors among general practitioners in China. J Am Board Fam Med 2020;33:456-459.

9. Chavez A, Bracamonte J, Kresin M, Yardley M, Grover M. High volume portal usage impacts practice resources. J Am Board Fam Med 2020;33:452-455.

10. Margolius D, Siff J, Teng K, Einstadter D, Gunzler D, Bolen S. Primary care physician factors associated with inbox message volume. J Am Board Fam Med 2020;33:460-462.

11. Bambekova PG, Liaw W, Phillips RL, Jr, Bazemore A. Integrating community and clinical data to assess patient risks with a Population Health Assessment Engine (PHATE). J Am Board Fam Med 2020;33: $463-467$.
12. Bonnell LN, Littenberg B, Wshah SR, Rose GL. A machine learning approach to identification of unhealthy drinking. J Am Board Fam Med 2020;33:397-406.

13. Ludden T, Shade L, Thomas J, et al. Novel models to identify census tracts for hepatitis $\mathrm{C}$ screening interventions. J Am Board Fam Med 2020;33: 407-416.

14. Schrager S, Ovsepyan V, Burnside E. Breast cancer screening in older women: the importance of shared decision making. J Am Board Fam Med 2020;33:473-480.

15. Hess C, Levy B, Hashmi AZ, et al. Subjective versus objective assessment of cognitive functioning in primary care. J Am Board Fam Med 2020;33: 417-425.

16. Friedman JL, Neutze D. The financial cost of medical assistant turnover in an academic family medicine center. J Am Board Fam Med 2020;33: 426-430.

17. Friedman SH, Cunningham CO, Lin J, Haramati LB, Levsky JM. Having a primary care provider is the strongest predictor of successful follow-up of participants in a clinical trial. J Am Board Fam Med 2020;33:431-439.

18. DeVoe JE. Primary care is an essential ingredient to a successful population health improvement strategy. J Am Board Fam Med 2020;33:468472 .

19. Bair H. The unexpected volunteer. J Am Board Fam Med 2020;33:481-483 